\title{
1 Whole-genome duplication and host genotype affect rhizosphere microbial communities
}

2 Julian C. B. Ponsford ${ }^{a}$, Charley J. Hubbard ${ }^{\mathrm{a}, \mathrm{b}}$, Joshua G. Harrison ${ }^{\mathrm{a}}$, Lois Maignien ${ }^{\mathrm{c}, \mathrm{d}}$ C. Alex

3 Buerkle ${ }^{\mathrm{a}, \mathrm{b}}$, Cynthia Weinig ${ }^{\mathrm{a}, \mathrm{b}, \mathrm{e}} \#$

a. Department of Botany, University of Wyoming, Laramie, WY, USA

b. Program in Ecology, University of Wyoming, Laramie, WY, USA

d. Laboratory of Microbiology of Extreme Environments, UMR 6197, Institut Européen de la Mer, Université de Bretagne Occidentale, Plouzane, France

11 Keywords: Arabidopsis thaliana, whole genome duplication, multinomial modeling, plant

12 microbe interactions

14 Funding: National Science Foundation grant: IOS-1444571 to LM and CW \& EPS-16557226 to

$15 \mathrm{CW}$ and $\mathrm{CAB}$. 


\section{Page 2 of 29}

Julian C. Bennett Ponsford

\section{Abstract}

18 influenced in part by host phenotype. Yet, the salient genetic architecture is often unknown.

19 Genome duplication events are common in the evolutionary history of plants, influence many

20 important plant traits, and may affect associated microbial communities. Using experimentally

21 induced whole genome duplication (WGD), we tested the effect of WGD on rhizosphere

22 bacterial communities in Arabidopsis thaliana. Specifically, we performed 16S rRNA amplicon

23 sequencing to characterize differences between microbiomes associated with specific host

24 genotypes (Columbia vs. Landsberg) and ploidy levels (diploid vs. tetraploid). We modeled

25 abundances of individual bacterial taxa by utilizing a hierarchical Bayesian framework, based on

26 the Dirichlet and multinomial distributions. We found that host genotype and host ploidy level

27 affected rhizosphere community composition, for instance, the microbiome of the tetraploid

28 Columbia genotype differed from that of other host genotypes. We then tested to what extent

29 microbiomes derived from a given host genotype or ploidy level affected plant performance by

30 inoculating sterile seedlings of each genotype with microbial communities harvested from a prior

31 generation. We found a negative effect of the tetraploid Columbia microbiome on growth of all

32 four plant genotypes. The findings suggest that while both host genotype and ploidy affect

33 microbial community assembly, bacterial communities found in association with only some host

34 genotypes may affect growth of subsequent plant generations. 
Julian C. Bennett Ponsford

\section{Importance}

37 Plants influence the composition of their associated microbial communities; yet the underlying

38 host genetic factors are often unknown. Genome duplication events are common in the

39 evolutionary history of plants and affect many plant traits, including the quality and quantity of

40 compounds exuded into the root zone, which can affect root-bound microbes. In Arabidopsis

41 thaliana, we characterized how whole-genome duplication affected the composition of

42 rhizosphere bacterial communities, and how bacterial communities associated with two host

43 plant genotypes and ploidy levels affected subsequent plant growth. We observed an interaction

44 in which ploidy level within one host genotype affected both bacterial community composition

45 and function. This research reveals how genome duplication, a widespread genetic feature of

46 both wild and crop plant species, influences the coexistence of bacterial taxa and affects plant

47 growth. 


\section{Introduction}

Plant-microbe interactions can exhibit a complete feedback cycle, in which changes in

53

54 the microbiome affect plant performance and the genetics of the plant host alter microbial community composition (1-3). The traits of bacterial taxa in plant-associated communities affect both host fitness and ecological function (4). Rhizosphere bacteria, in particular, affect many aspects of plant performance, such as increasing access to nutrients (5), relieving abiotic and biotic stress (6), and promoting growth (7). Even slight changes in the rhizosphere microbiome can affect host plant performance (8). For instance, Korir et al. (2017) found that increased abundance of one taxon, Bacillus megaterium, led to enhanced nitrogen access and growth of Phaseolus vulgaris in field conditions (9). Wholesale changes in the abundance of taxa comprising rhizosphere microbiomes also affects plant performance $(10,11)$. For example, in Arabidopsis thaliana, differences in microbial community composition attributable to past or nearby plant communities strongly influenced host growth $(12,13)$.

A plant host's genetic background can also affect the composition of microbiomes consisting of thousands of taxa (14-16). For instance, over a range of environmental conditions, host genotype in maize explains on average $\sim 19 \%$ of the variance in relative abundance of root microbial taxa (17). Among host genotypes, allelic variation segregating at loci with diverse functions could potentially contribute to differences in rhizosphere community composition. The contribution of specific host-plant loci and pathways has been demonstrated experimentally using genetic knock-outs or transgenic overexpression $(18,19)$. Genetic manipulation to shift the plant circadian clock by \pm 4 hours explained $\sim 22 \%$ of the variance in rhizosphere bacterial communities among experimental Arabidopsis lines (13). However, the number of studies 
73 characterizing causal genetic factors is small, and the extent to which specific host genetic and

74 genomic features alter the assembly and function of microbial communities remains largely

75 unknown, despite the demonstrably important effect of the rhizosphere microbiome on host plant

76 performance.

Plants influence rhizosphere microbial communities via root exudation of small

78 molecular-weight organic compounds (20-22). For simple symbioses consisting of one plant and

79 one microbial taxon, such as between legumes and Rhizobia, the host genetic mechanisms that

80 underlie these interactions are increasingly well characterized (23-25). How more complex

81 genetic mechanisms affect associated root microbial communities is less clear. Whole-genome

82 duplication (WGD) is one genetic feature of host plants that could potentially influence

microbial community composition via root exudation. WGD can lead to changes in cell size, life-

84 history, and physiology, which may influence numerous other phenotypes $(26,27)$. WGD also

85 occurs naturally in wild populations and is ubiquitous in the evolutionary history of plants and in the domestication history of many crop species (28).

89 besides those associated with genome duplication (29). Therefore, the comparison of rhizosphere microbiomes between $A$. thaliana tetraploid genotypes developed from inbred diploid lines

91 provides a basis for testing the effects of host ploidy level on microbial community composition,

92 without the confounding effects of allelic variation or fixed heterozygosity between tetraploids

93 and diploid progenitors. Tetraploidy can induce changes in core metabolic pathways such as the

94 tricarboxylic acid cycle (TCA), malate and citrate concentrations, and potassium uptake in $A$. 
thaliana $(30,31)$. These phenotypic shifts may alter root exudate profiles or other phenotypes that consequentially change microbial colonization and community composition. disparate communities compared to diploid hosts, then we predicted that differences in these communities could affect plant performance. diploid genotypes: Columbia (Col-2x) and Landsberg erecta (Ler-2x) and their tetraploid counterparts (Col-4x CS922178) and (Ler-4x CS3900). Tetraploid genotypes were multiple generations removed from initial colchicine treatment, and therefore can be assumed to be mutationally stable (32). In our first experiment, each genotype was planted into sterilized

111 potting mix and inoculated with a microbial community from the Catsburg region of Durham,

112 North Carolina, USA $\left(36.0622^{\circ} \mathrm{N},-78.8496^{\circ} \mathrm{W}\right)$, a site with a history of $A$. thaliana growth. The microbiomes associated with each host plant genotype were characterized by $16 \mathrm{~S}$ rRNA gene

114 amplicon sequencing in the first experiment and tested for effects on growth of a second 115 generation of plants in a second experiment. 
117 Tween, and autoclave sterilized reverse osmosis purified water $\left(\mathrm{RO} \mathrm{H}_{2} \mathrm{O}\right)$. Seeds were

118 thoroughly rinsed in $\mathrm{RO} \mathrm{H}_{2} \mathrm{O}$ to remove any remaining detergents. Seeds were placed in $1.5 \mathrm{~mL}$ 119 tubes containing $1 \mathrm{~mL} \mathrm{RO} \mathrm{H} \mathrm{H}_{2} \mathrm{O}$ and stored at $4{ }^{\circ} \mathrm{C}$ for seven days and then placed on greenhouse 120 benches under natural $14 \mathrm{hr}$ photoperiods to induce synchronous germination (33). On the day

121 root radicles were observed, seeds were transferred to 2-inch diameter net pots filled with a

122 mixture of autoclaved Redi-Earth Potting Mix (Sungro Horticulture, Agawam, MA, USA) and 2

$123 \mathrm{~mL}$ of liquid inoculant (described below). To ensure sterility, potting mix was autoclaved on a

124 wet cycle for $60 \mathrm{~min}$ at $121^{\circ} \mathrm{C}$, allowed to rest for at least one hour and autoclaved for another 60

125 min. No microbes could be cultured on tryptic soy agar media using serial dilutions of

126 autoclaved soil as inoculum. To create inoculants for the first experiment, $60 \mathrm{~g}$ of the Catsburg

127 soil was mixed with $540 \mathrm{~mL}$ of autoclaved $\mathrm{RO} \mathrm{H}_{2} \mathrm{O}$ and sieved through $1000 \mu \mathrm{m}, 212 \mu \mathrm{m}$ and

$12845 \mu \mathrm{m}$ sterile sieves to remove nematodes that could potentially affect plant performance (34).

129 The Catsburg site not only has a well-documented occurrence of naturalized A. thaliana

130 populations but also has a soil $\mathrm{pH}$ approximately identical to the potting substrate, which

131 minimized potential selection by the common soil matrix on microbial community composition $132(35-37)$.

For the second experiment, we used four randomly selected plant-conditioned soil

134 samples from each host genotype to create inoculums. Soil was combined by genotype, manually

135 homogenized, and used to create inoculum as above. In all experiments, after ten days of growth,

136 seedlings were thinned to one plant per pot. All experiments were performed at the Williams

137 Conservatory or Agricultural Experiment Station at the University of Wyoming. 
141 To measure the influence of host ploidy on rhizosphere bacterial community composition, 20

142 replicates of Col-2x, Col-4x, Ler-2x, and Ler-4x were planted in a fully randomized four block

143 design. To avoid confounding the effects of ploidy with developmental stage, eight rhizosphere 144 samples from each genotype were collected on day 24 , by which time all plants displayed visible 145 elongation of the primary inflorescence from the apical meristem $(\mathrm{N}=32)$. Unharvested plants

146 were allowed to grow until senescence to quantify additional traits. To account for variation in

147 microbial communities due to greenhouse conditions and intrinsic variation in soil independent

148 of plant host effects, we collected soil from empty pots containing only soil that were potted 149 simultaneously with our experiment $(\mathrm{N}=7)$.

153 host genotypes, we used a fully factorial design with four host plant genotypes grown in four 154 host-influenced microbiomes (harvested from the host genotypes in expt. 1). 40 replicates of 155 each plant genotype were grown in sterilized potting mix inoculated with one of the four 156 rhizosphere microbiomes from plant-conditioned soil in a fully randomized block design. Plants

157 were checked daily for bolting and flowering. Upon the first plant bolting, a subset of plants was 158 collected for above- and belowground biomass $(\mathrm{N}=382)$ to measure plant growth and resource 
159 allocation. A subset of plants were allowed to senesce and seeds harvested to quantify seed mass

$160(\mathrm{~N}=152)$. All phenotypic measurements were performed following Rubin et al (38).

164 uprooting plants, manually agitating plants, removing loosely adhering soil particles, placing

167 a total soil mass of no more than $250 \mathrm{mg}$ was transferred from each tube into a sterile Qiagen

168 PowerSoil (Qiagen, Valencia, CA) bead tube. DNA was extracted following manufacturer's

169 instructions. Extracted DNA was shipped to the Marine Biological Laboratories (Woods Hole,

170 MA, USA) for amplification and sequencing of the V4-V5 (primers 518f and 926r) region of the

171 16S rRNA gene (40) on an Illumina MiSeq (Illumina, San Diego, CA, USA).

\section{Sequence and data analysis}

We used the R package dada2 (ver. 1.5.8) to filter and trim reads based on quality,

174 estimate the error rate using 1000000 reads, dereplicate reads, infer amplicon sequence variants

175 (ASV), merge paired end reads, remove chimeras, and assign unique sequences to taxa using the

176 Silva 16 S database (ver. 128) $(41,42)$. Next, we ascertained the relative abundance of

177 operational taxa by quantifying unique sequences and amplicon sequence variants using the

178 default settings in the microbiome R package (43). Raw sequences were uploaded to the NIH

179 NCBI Short Read Archive under project ID PRJNA474006. 
Dissimilarity analyses identify coarse-grained changes in community composition across treatments, which arise from the combined effects of all community members. Yet, significant differences in relative abundance may exist when comparing individual taxa between treatments that are not discernible when aggregating effects of whole communities. To test for differences in the relative abundances of individual taxa between treatment levels (contrasts of host ploidy and host genotype), we used a hierarchical Bayesian modelling approach reliant upon the

187 explicitly accounts for the compositional nature of community sampling (whether in sequencing data or any finite number of taxa observations from an assemblage), readily allows informationsharing among replicates within a category and obtains estimates of the relative abundance of each microbial taxon, while propagating uncertainty in those estimates. We estimated differences in the relative abundance of each microbial taxon between experimental treatments through comparison of parameter estimates as per Harrison et al. (2020) (44). of each taxon in a replicate, denoted as a vector of parameters $(\boldsymbol{p})$. These multinomial parameters were informed by a Dirichlet distribution, with parameters characterizing the expected

196 frequencies of each taxon $\left(\pi^{*} \Theta\right)$, where $\pi$ is a vector describing the expected relative abundance 197 of each taxon in the sampling group and $\Theta$ is an intensity parameter that models among-replicate 198 variation $(44,46)$. To quantify differences in the relative abundance of taxa between groups, we 199 calculated the posterior probability distribution for the difference in $\pi_{\mathrm{i}}$ parameters between groups for some taxon $i$. The probability of an effect of treatment on a focal taxon can be determined by the location of zero in this distribution of differences. Following convention, if 
$95 \%$ or more of the distribution did not overlap zero, then there was little evidence that the

203 relative abundance of the focal taxon differed between treatment groups.

The DMM offers several advantages over existing analytical methodologies. First, parameters were estimated while propagating uncertainty, thus avoiding cumbersome multiple comparison correction, and precluding the use of p-values. Second, information was shared among replicates and treatment groups. Third, rarefaction is unnecessary because analyses are performed on taxon frequencies, which are estimated using information from all replicates within a sampling group. Fourth, the Dirichlet and multinomial distributions have interdependent parameters that reflect the compositional nature of sequencing data, thus we model the composition as a whole as opposed to estimating the relative abundance of each taxon separately, as in DESeq2 (47).

DMM was specified in the Stan probabilistic programming language and implemented

214 through the rstan (ver. 2.18.2) package in the R statistical computing environment (ver. 3.6.0)

$215(48,49)$. For each of four chains, the sampler was run for 1500 steps as a burn-in period and was

216 followed by an additional 1000 steps (a total of 4000 samples were drawn from the posterior

217 distributions of focal parameters [ $\boldsymbol{\pi}$ from each sampling group]). The Gelman-Rubin statistic was

218 computed to measure convergence among chains (50). Separate models were constructed for the

219 following comparisons: all diploid versus all tetraploid hosts, Columbia versus Landsberg erecta,

220 and Columbia tetraploid versus all other treatments (pooled).

222 to confirm 16 S rRNA identifications generated using the SILVA database $(51,52)$. We report

223 species level identification in cases where reads align 100\% with entries in the $16 \mathrm{~S}$ ribosomal 
224 RNA sequences database, and report bacterial family if genus level resolution is not corroborated by SILVA (53).

To assess effects on plant performance in experiment 2, we used fixed effect, three-way

227 ANOVAs, where inoculum, genotype, and block were the explanatory variables. For purposes of 228 data representation, residuals were plotted after statistically accounting for the effect of genotype 229 and block. Finally, we used planned comparisons to contrast plant performance between plants grown in the Col-2x versus Col-4x inoculums and Ler-2x versus Ler-4x inoculums.

\section{Results}

Sequencing results

After quality filtering and chimera removal in dada2 as well as removal of bacterial taxa occurring in plant-less pots and removal of 16S rRNA sequences from chloroplasts, mitochondria, and Eukaryotes, 1647741 processed reads remained from an initial 3282410 raw reads. We retained 36033 reads to 143254 reads per plant rhizosphere (Supplemental

Figure 1). In total, there were 2689 microbial taxa (ASVs) present.

241 differences in the abundance of individual taxa among treatments that might not be evident in

242 whole community dissimilarity analyses. Based on this approach we identified 25 taxa that were

243 significantly enriched in both Ler genotypes and 29 taxa that were more abundant in the Col

244 genotypes (Figure 1a). A taxon of genus Pedobacter was the most highly enriched in Ler 
associated bacterial communities with an 8-fold increase. In Col bacterial communities, the most enriched taxon was Pseudomonas at a 4.8-fold increase in abundance. DMM also identified 17 taxa that were significantly enriched in all diploid genotypes. Of these taxa, the most enriched taxon was a member of the genus Bacillus, enriched 3.1-fold relative to tetraploid communities. Tetraploid communities' most enriched member was Mucilaginibacter, which was present at 4fold greater relative abundance compared to rhizosphere microbiomes in diploids. 23 taxa were significantly enriched across both tetraploid genotypes (Figure 1b). Our model identified 16 taxa

252 as higher abundance in the Columbia tetraploid rhizosphere and 30 taxa enriched across the

253 bacterial microbiomes of the other three host genotypes. In Col-4x, a bacterium identified as 254 Sphingomonas had the highest change in abundance at 6-fold. Conversely, a taxon of genus 255 Pedobacter was enriched in all other microbiomes. This taxon appeared at 5.8-fold greater 256 frequency in these microbiomes than Col-4x. Across all comparisons, ASVs within the phylum 257 Proteobacteria were more commonly differentially abundant than taxa within any other phylum. Effects of rhizosphere microbes on plant performance

When microbiomes from plant-conditioned soil were harvested following experiment 1, and used as inoculant in experiment 2, plants grown in soils inoculated with the Col-4x

261 microbiome had significantly lower aboveground and belowground biomass compared to plants 262 grown in soils inoculated with Col-2x microbiome $(\mathrm{P}<0.001 \& \mathrm{P}=0.012)$ or microbiomes

263 influenced by either of the two Ler genotypes (Figure $2 \mathbf{a b} ; \mathrm{P}<0.001 \& \mathrm{P}<0.001$ ). The soil

264 microbiome had no effect on phenological characteristics or fruit number (Supplemental Table 2652 2). 


\section{Discussion}

Whole genome duplication is estimated to have occurred across $30-70 \%$ of the angiosperm phylogeny over its evolutionary history and is a common genetic feature of many economically important plants (54). We found that host genotype and WGD influenced

271 numerous individual taxa within the rhizosphere microbiome. Furthermore, host-genotype

272 specific effects on rhizosphere microbiomes influenced plant growth. In contrast to prior studies

273 (55), our experiments also utilized a soil with a history of Arabidopsis occurrence as inoculant.

274 This should, in principle, allow genotypes to assemble root microbiota from the existing soil 275 microbiomes. accessions of $A$. thaliana have found a link between genotype and rhizosphere bacteria $(15,20)$.

278 These studies report a $<10 \%$ shift in composition between the Ler and Col genotypes, which we 279 corroborate here. As noted above, we identified many individual taxa associated with host

280 ploidy level (Figure 1a). This provides support for the hypothesis that these specific taxa are 281 directly responsive to genome duplication. Although the causal physiological mechanisms 282 remain unclear in the current study, one candidate mechanism is root exudation. Previous studies 283 suggest that carbon root exudates strongly affect the occurrence and abundance of microbial taxa 284 in the rhizosphere $(2,56)$, and these exudates can be influenced by genome duplication $(30)$.

285 Consequently, shifts in root exudates, or other metabolites produced by the plant, in response to 286 WGD could be partially responsible for the association between ploidy and the relative 287 abundance of microbial taxa that we observed $(57,58)$. Given that the number of microbial taxa 
conclude that while host ploidy level affects the abundance of some taxa, it may not lead to

\section{0}

291

292

293

294

295 community composition by affecting the relative abundance of certain bacterial taxa. In some genetic backgrounds, plant ploidy level affects microbial function, as indicated by enhanced broad-scale changes in the rhizosphere microbiome.

We found that differences in the rhizosphere bacterial microbiome lead to differences in host performance [Figure 2: 23, 61, 62]. Here, plants grown in soils inoculated with microbial rhizosphere communities harvested from Col-4x plants had reduced vigor compared to plants grown in soils inoculated with microbial communities from all other genotypes (Figure 2). One bacterial species, Novaherbaspirillium autotrophicum, was identified as being significantly enriched in the Columbia tetraploid genotype. $N$. autotrophicum was identified as a facultative autotroph capable of denitrification, isolated from rice paddy fields (61). The greater abundance of this microbe in the Columbia tetraploid community may point to changes in rhizobial community in plants inoculated with this microbiome. The greater abundance of $N$. autotrophicum may result in a decrease in available nitrogen in the rhizosphere causing lower overall growth in the plant host. This loss of biomass may have effects on nutrient cycling or survivability in stressful environments. Further, the effect of taxa such as $N$. autotrophicum may be especially impactful in the context of mixed populations of diploid and tetraploid individuals, where stressful conditions could be compounded or mitigated by host-associated microbes (62).

\section{Conclusions}

In sum, we have shown that whole genome duplication influences rhizosphere bacterial above and belowground plant biomass in the Col-2x versus Col-4x genotypes. Multiple bacterial 
311 taxa are affected by host ploidy level, irrespective of host genetic background. The ASVs

312 enriched (or reduced) in the rhizosphere of tetraploid hosts could help explain the advantages

313 tetraploids appear to have in stressful environments $(63,64)$. Given the prevalence of WGD

314 among plants in both natural and agricultural systems, our results highlight a novel mechanism

315 by which plant evolutionary history influences the root-associated microbiome, thereby affecting

316 plant phenotype.

\section{Acknowledgments}

319 Computing was performed in the Teton Computing Environment at the Advanced Research

320 Computing Center, University of Wyoming, Laramie (https://doi.org/10.15786/M2FY47). This

321 work was supported by the National Science Foundation grants IOS-1444571 to CW, LM and

322 EPS-16557226 to CW and CAB. We would like to thank Lindsay Leverett for collecting soil,

323 and Meredith Pratt and Ryan Pendleton for help with experimental and greenhouse maintenance 


\section{Conflict of Interests}

The authors report no conflicts of interest.

\section{References}

329 1. Schlaeppi K, Bulgarelli D. 2015. The Plant Microbiome at Work. Mol Plant-Microbe Interact MPMI 212:212-217.

2. Chaparro JM, Badri D V, Vivanco JM. 2013. Rhizosphere microbiome assemblage is affected by plant development. ISME J 8:790-803.

3. Van Nuland ME, Bailey JK, Schweitzer JA. 2017. Divergent plant-soil feedbacks could alter future elevation ranges and ecosystem dynamics. Nat Ecol Evol 1:0150.

4. Talbot JM, Bruns TD, Taylor JW, Smith DP, Branco S, Glassman SI, Erlandson S,

5. Richardson AE, Simpson RJ. 2011. Soil Microorganisms Mediating Phosphorus 
Page 18 of 29

Julian C. Bennett Ponsford

$344 \quad$ 7. Bulgarelli D, Schlaeppi K, Spaepen S, van Themaat EVL, Schulze-Lefert P. 2013.

Structure and Functions of the Bacterial Microbiota of Plants. Annu Rev Plant Biol

346 64:807-838.

8. Henning JA, Weston DJ, Pelletier DA, Timm CM, Jawdy SS, Classen AT. 2016. Root bacterial endophytes alter plant phenotype, but not physiology. PeerJ 4:e2606.

9. Korir H, Mungai NW, Thuita M, Hamba Y, Masso C. 2017. Co-inoculation Effect of Rhizobia and Plant Growth Promoting Rhizobacteria on Common Bean Growth in a Low Phosphorus Soil. Front Plant Sci 08:141.

352

353

10. Wagner MR, Lundberg DS, Coleman-Derr D, Tringe SG, Dangl JL, Mitchell-Olds T. 2014. Natural soil microbes alter flowering phenology and the intensity of selection on flowering time in a wild Arabidopsis relative. Ecol Lett 17:717-726.

11. Zolla G, Badri D V., Bakker MG, Manter DK, Vivanco JM. 2013. Soil microbiomes vary in their ability to confer drought tolerance to Arabidopsis. Appl Soil Ecol 68:1-9.

12. Sugiyama A, Bakker MG, Badri D V., Manter DK, Vivanco JM. 2013. Relationships between Arabidopsis genotype-specific biomass accumulation and associated soil microbial communities. Botany 91:123-126.

13. Hubbard CJ, Brock MT, van Diepen LT, Maignien LL, Ewers BE, Weinig C. 2017. The plant circadian clock influences rhizosphere community structure and function. ISME J doi:in press.

14. Wagner MR, Lundberg DS, Del Rio TG, Tringe SG, Dangl JL, Mitchell-Olds T. 2016. Host genotype and age shape the leaf and root microbiomes of a wild perennial plant. Nat 
Commun 7:1-15.

366

367

368

369

370

371

372

373

374

375

376

377

378

379

380

381

382

383

15. Lundberg DS, Lebeis SL, Paredes SH, Yourstone S, Gehring J, Malfatti S, Tremblay J, Engelbrektson A, Kunin V, Rio TG del, Edgar RC, Eickhorst T, Ley RE, Hugenholtz P, Tringe SG, Dangl JL. 2012. Defining the core Arabidopsis thaliana root microbiome. Nature 488:86-90.

16. Marques JM, da Silva TF, Vollu RE, Blank AF, Ding G-C, Seldin L, Smalla K. 2014. Plant age and genotype affect the bacterial community composition in the tuber rhizosphere of field-grown sweet potato plants. FEMS Microbiol Ecol 88:424-435.

17. Peiffer JA, Spor A, Koren O, Jin Z, Tringe SG, Dangl JL, Buckler ES, Ley RE. 2013. Diversity and heritability of the maize rhizosphere microbiome under field conditions. Proc Natl Acad Sci 110:6548-6553.

18. Berendsen RL, Pieterse CMJ, Bakker PAHM. 2012. The rhizosphere microbiome and plant health. Trends Plant Sci 17:478-486.

19. Agler MT, Ruhe J, Kroll S, Morhenn C, Kim S-T, Weigel D, Kemen EM. 2016. Microbial Hub Taxa Link Host and Abiotic Factors to Plant Microbiome Variation. PLoS Biol 14:e1002352.

20. Jones DL, Nguyen C, Finlay RD. 2009. Carbon flow in the rhizosphere: Carbon trading at the soil-root interface. Plant Soil.

21. Walker TS. 2003. Root Exudation and Rhizosphere Biology. PLANT Physiol 132:44-51.

22. Dennis PG, Miller AJ, Hirsch PR. 2010. Are root exudates more important than other 
Page 20 of 29

Julian C. Bennett Ponsford

sources of rhizodeposits in structuring rhizosphere bacterial communities? FEMS

Microbiol Ecol 72:313-327.

23. Bravo A, York T, Pumplin N, Mueller LA, Harrison MJ. 2016. Genes conserved for arbuscular mycorrhizal symbiosis identified through phylogenomics. Nat Plants 2:15208.

24. Sanchez-Contreras M, Bauer WD, Gao M, Robinson JB, Allan Downie J. 2007. Quorumsensing regulation in rhizobia and its role in symbiotic interactions with legumes. Philos

Trans R Soc B Biol Sci 362:1149-1163.

25. Udvardi M, Poole PS. 2013. Transport and Metabolism in Legume-Rhizobia Symbioses. Annu Rev Plant Biol 64:781-805.

26. Garbutt K, Bazzaz FA. 1983. Leaf demography, flower production and biomass of diploid 395 and tetraploid populations of phlox-drummondii hook on a soil-moisture gradient. New Phytol. WileyNew Phytologist Trust.

27. Stebbins GL. 1971. Chromosomal Evolution in Higher PlantsContemporary Biology. Edward Arnold Ltd., London.

28. Ramsey J, Ramsey TS. 2014. Ecological studies of polyploidy in the 100 years following its discovery. Philos Trans R Soc B Biol Sci 369:20130352-20130352.

401 29. Breuer C, Stacey NJ, West CE, Zhao Y, Chory J, Tsukaya H, Azumi Y, Maxwell A, 
Page 21 of 29

Julian C. Bennett Ponsford

405

406

407

408

409

410

411

412

413

414

415

416

417

418

419

420

421

422

423

424

425

30. Vergara F, Kikuchi J, Breuer C. 2016. Artificial Autopolyploidization Modifies the Tricarboxylic Acid Cycle and GABA Shunt in Arabidopsis thaliana Col-0. Sci Rep $6: 26515$

31. Chao D-Y, Dilkes B, Luo H, Douglas A, Yakubova E, Lahner B, Salt DE. 2013.

Polyploids Exhibit Higher Potassium Uptake and Salinity Tolerance in Arabidopsis. Science (80- ) 341:658-659.

32. Hollister JD, Arnold BJ, Svedin E, Xue KS, Dilkes BP, Bomblies K. 2012. Genetic Adaptation Associated with Genome-Doubling in Autotetraploid Arabidopsis arenosa. PLoS Genet 8:e1003093.

33. Kerwin R, Feusier J, Corwin J, Rubin M, Lin C, Muok A, Larson B, Li B, Joseph B, Francisco M, Copeland D, Weinig C, Kliebenstein DJ. 2015. Natural genetic variation in Arabidopsis thaliana defense metabolism genes modulates field fitness. Elife 2015:1-28.

34. van de Voorde TFJ, van der Putten WH, Bezemer TM. 2012. Soil inoculation method determines the strength of plant-soil interactions. Soil Biol Biochem 55:1-6.

35. Mauricio R. 1998. Costs of Resistance to Natural Enemies in Field Populations of the Annual Plant Arabidopsis thaliana. Am Nat 151:20-28.

36. Fierer N, Jackson RB. 2006. The diversity and biogeography of soil bacterial communities. Proc Natl Acad Sci 103:626-631.

37. Lauber CL, Hamady M, Knight R, Fierer N. 2009. Pyrosequencing-based assessment of soil $\mathrm{pH}$ as a predictor of soil bacterial community structure at the continental scale. Appl Environ Microbiol 75:5111-5120. 
Page 22 of 29

Julian C. Bennett Ponsford

38. Rubin MJ, Brock MT, Weinig C, Baker RL, Wilcox S, Anderson K, Seth J, Rubin MJ. 2018. Circadian rhythms are associated with shoot architecture in natural settings. New Phytol 219.

39. Bulgarelli D, Rott M, Schlaeppi K, Ver Loren van Themaat E, Ahmadinejad N, Assenza F, Rauf P, Huettel B, Reinhardt R, Schmelzer E, Peplies J, Gloeckner FO, Amann R, Eickhorst T, Schulze-Lefert P. 2012. Revealing structure and assembly cues for Arabidopsis root-inhabiting bacterial microbiota. Nature 488:91-5.

40. Huse SM, Young VB, Morrison HG, Antonopoulos DA, Kwon J, Dalal S, Arrieta R, Hubert NA, Shen L, Vineis JH, Koval JC, Sogin ML, Chang EB, Raffals LE. 2014. Comparison of brush and biopsy sampling methods of the ileal pouch for assessment of mucosa-associated microbiota of human subjects. Microbiome 2:5.

41. Callahan BJ, McMurdie PJ, Rosen MJ, Han AW, Johnson AJA, Holmes SP. 2016. DADA2: High-resolution sample inference from Illumina amplicon data. Nat Methods $13: 581-583$.

42. Quast C, Pruesse E, Yilmaz P, Gerken J, Schweer T, Yarza P, Peplies J, Glöckner FO. 2013. The SILVA ribosomal RNA gene database project: Improved data processing and web-based tools. Nucleic Acids Res 41:D590-D596.

43. Shetty SA, Hugenholtz F, Lahti L, Smidt H, de Vos WM. 2017. Intestinal microbiome landscaping: Insight in community assemblage and implications for microbial modulation strategies. FEMS Microbiol Rev 41:182-199.

44. Harrison JG, Calder WJ, Shastry V, Buerkle CA. 2020. Dirichlet-multinomial modelling 
Page 23 of 29

Julian C. Bennett Ponsford

outperforms alternatives for analysis of microbiome and other ecological count data. Mol Ecol Resour 20:481-497.

45. Holmes I, Harris K, Quince C. 2012. Dirichlet multinomial mixtures: Generative models for microbial metagenomics. PLoS One 7.

46. Fordyce JA, Gompert Z, Forister ML, Nice CC. 2011. A Hierarchical Bayesian Approach to Ecological Count Data: A Flexible Tool for Ecologists. PLoS One 6:e26785.

47. Love MI, Huber W, Anders S. 2014. Moderated estimation of fold change and dispersion for RNA-seq data with DESeq2. Genome Biol 15:550.

48. Carpenter B, Gelman A, Hoffman MD, Lee D, Goodrich B, Betancourt M, Brubaker M, Guo J, Li P, Riddell A. 2017. Stan: A Probabilistic Programming Language. J Stat Softw 76:1-32.

49. Stan Development Team. 2018. rstan: the R interface to Stan v. 2.18.2.

50. Besag J, Green P, Higdon D, Mengersen K. 1989. Institute of Mathematical Statistics is collaborating with JSTOR to digitize, preserve, and extend access to Statistical Science. ${ }^{\circledR}$ www.jstor.org. Statistics (Ber) 10:409-435.

51. Altschul SF, Gish W, Miller W, Myers EW, Lipman DJ. 1990. Basic local alignment search tool. J Mol Biol 215:403-410.

52. Johnson M, Zaretskaya I, Raytselis Y, Merezhuk Y, McGinnis S, Madden TL. 2008. NCBI BLAST: a better web interface. Nucleic Acids Res 36.

53. Agarwala R, Barrett T, Beck J, Benson DA, Bollin C, Bolton E, Bourexis D, Brister JR, 
Bryant SH, Canese K, Cavanaugh M, Charowhas C, Clark K, Dondoshansky I, Feolo M, Information. Nucleic Acids Res 46:D8-D13.

54. Alix K, Gérard PR, Schwarzacher T, Heslop-Harrison JSP. 2017. Polyploidy and interspecific hybridization: Partners for adaptation, speciation and evolution in plants. Ann Bot. Oxford University Press.

55. Bai Y, Müller DB, Srinivas G, Garrido-Oter R, Potthoff E, Rott M, Dombrowski N, 
Page 25 of 29

Julian C. Bennett Ponsford

Microbiome 5:65.

490

491

492

493

494

495

496

497

498

499

500

501

502

503

504

505

506

507

508

57. Edger PP, Heidel-Fischer HM, Bekaert M, Rota J, Glöckner G, Platts AE, Heckel DG, Der JP, Wafula EK, Tang M, Hofberger JA, Smithson A, Hall JC, Blanchette M, Bureau TE, Wright SI, dePamphilis CW, Eric Schranz M, Barker MS, Conant GC, Wahlberg N, Vogel H, Pires JC, Wheat CW. 2015. The butterfly plant arms-race escalated by gene and genome duplications. Proc Natl Acad Sci 112:8362-8366.

58. Lebeis SL, Paredes SH, Lundberg DS, Breakfield N, Gehring J, McDonald M, Malfatti S, del Rio TG, Jones CD, Tringe SG, Dangl JL, Glavina del Rio T, Jones CD, Tringe SG, Dangl JL. 2015. Salicylic acid modulates colonization of the root microbiome by specific bacterial taxa. Science (80- ) 349:860-864.

59. Badri D V., Zolla G, Bakker MG, Manter DK, Vivanco JM. 2013. Potential impact of soil microbiomes on the leaf metabolome and on herbivore feeding behavior. New Phytol 198:264-273.

60. Fitzpatrick CR, Copeland J, Wang PW, Guttman DS, Kotanen PM, Johnson MTJ. 2018. Assembly and ecological function of the root microbiome across angiosperm plant species. Proc Natl Acad Sci U S A 115:E1157-E1165.

61. Ishii S, Ashida N, Ohno H, Segawa T, Yabe S, Otsuka S, Yokota A, Senoo K. 2017. Noviherbaspirillum denitrificans sp. nov., a denitrifying bacterium isolated from rice paddy soil and Noviherbaspirillum autotrophicum sp. nov., a denitrifying, facultatively autotrophic bacterium isolated from rice paddy soil and proposal to reclassify H. Int J Syst Evol Microbiol 67:1841-1848. 
bioRxiv preprint doi: https://doi.org/10.1101/822726; this version posted June 6, 2020. The copyright holder for this preprint (which was not certified by peer review) is the author/funder, who has granted bioRxiv a license to display the preprint in perpetuity. It is made available under aCC-BY-NC-ND 4.0 International license.

Page 26 of 29

Julian C. Bennett Ponsford

62. Segraves KA. 2017. The effects of genome duplications in a community context. New

Phytol 215:57-69.

512

63. Bomblies K, Madlung A. 2014. Polyploidy in the Arabidopsis genus. Chromosom Res.

64. Van de Peer Y, Mizrachi E, Marchal K. 2017. The evolutionary significance of

a)

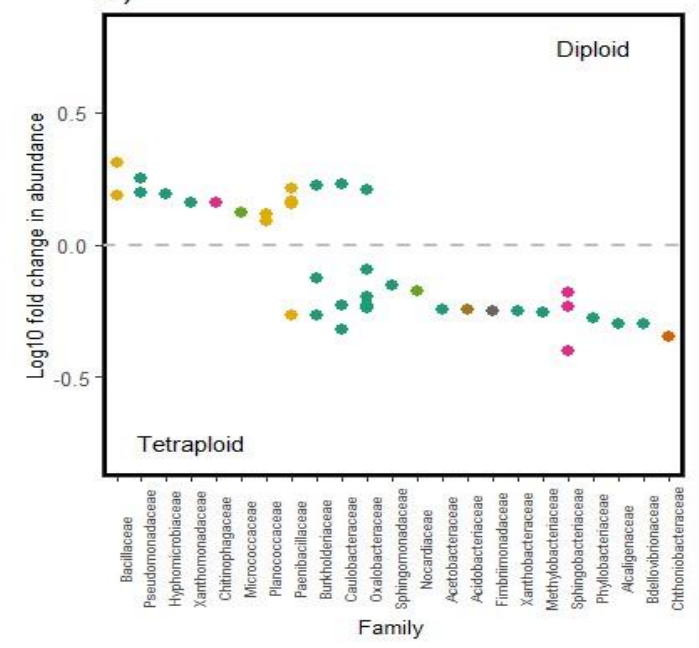

b)

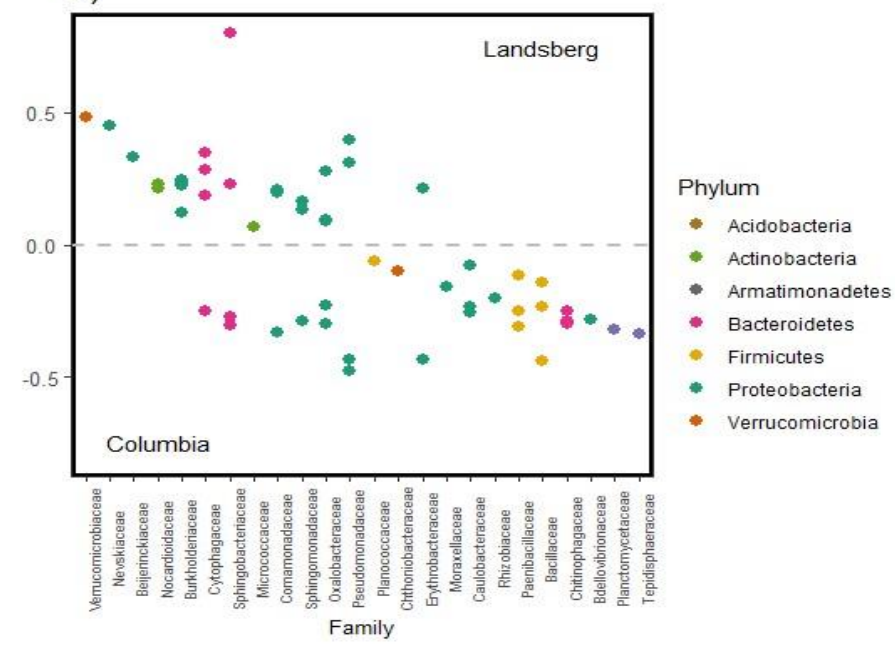

Figure 1: Genotype and ploidy differentially affect rhizosphere bacterial community abundances between the Col and Ler genotypes. a) Families identified as more abundant in the diploid rhizosphere are shown above grey line, and those more abundant in the tetraploid rhizosphere appear below grey line. b) Families identified as more abundant in the Landsberg rhizosphere are shown above grey line, and those more abundant in the rhizosphere of tetraploids appear below grey line. Log10 fold changes were calculated from relative abundance estimates obtained through hierarchical Bayesian modeling of read counts (see main text). Points represent individual ASVs within families. 
bioRxiv preprint doi: https://doi.org/10.1101/822726; this version posted June 6, 2020. The copyright holder for this preprint (which was not certified by peer review) is the author/funder, who has granted bioRxiv a license to display the preprint in perpetuity. It is made available under

\title{
Page 27 of 29
}

\author{
Julian C. Bennett Ponsford
}
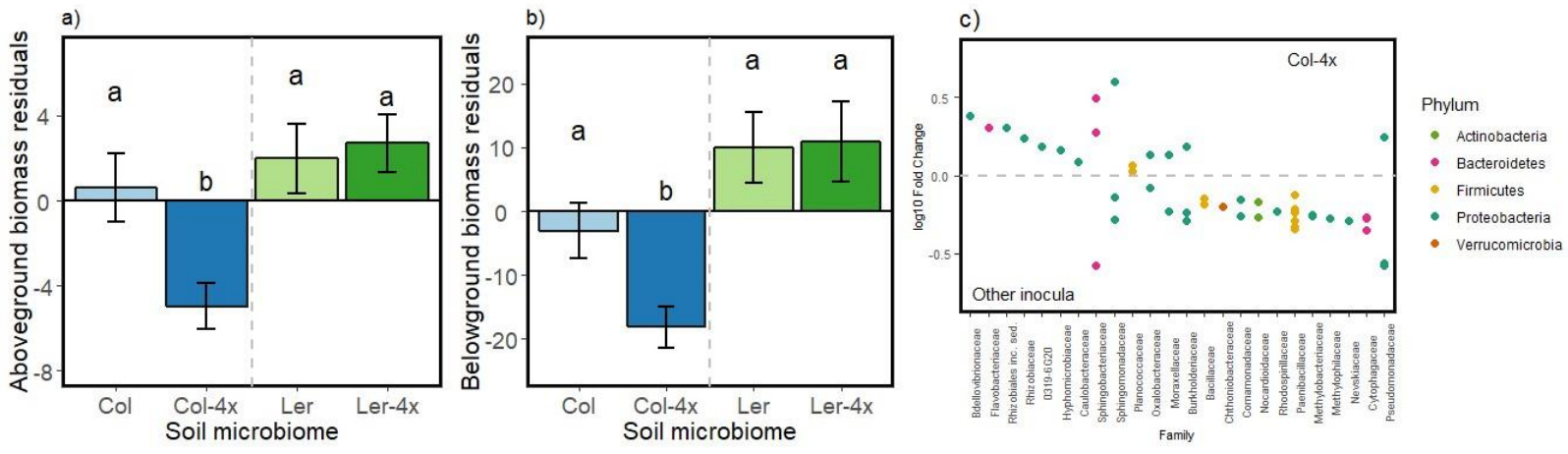

Figure 2: a,b) Residuals of observed growth differences in above and belowground biomass for plants grown in soils inoculated with microbiomes shaped by each genotype, with effects of block removed. All genotypes inoculated with Columbia tetraploid microbiome had significantly reduced above and below ground biomass. c) Bacterial families identified as more abundant in the Columbia tetraploid rhizosphere are shown above grey line. Those more abundant in the rhizosphere of all other inoculums appear below grey line. Log10 fold changes were calculated from relative abundance estimates obtained through hierarchical Bayesian modeling of read counts (see main text). Points represent individual ASVs within families 
bioRxiv preprint doi: https://doi.org/10.1101/822726; this version posted June 6, 2020. The copyright holder for this preprint (which was not certified by peer review) is the author/funder, who has granted bioRxiv a license to display the preprint in perpetuity. It is made available under

Page 28 of 29

Julian C. Bennett Ponsford

521 Supplemental Tables and Figures

522

523 Supplemental Table 1: Number of reads at each step of sequence data processing

\section{Processing Step}

Initial

Filtering and Trimming, Sample Inference,

Chimera Removal

Removal of Chloroplast, Mitochondrial,

Eukaryotic DNA and Plant-less blanks

\section{Number of Reads}

3282410

1985490

1647741

525 Supplemental Table 2: Effect of inoculum shaped by plant genotype on plant performance

\begin{tabular}{cc}
\hline Trait & P - Value \\
\hline Aboveground biomass & $<0.001$ \\
Belowground biomass & $<0.001$ \\
Root : Shoot & $\mathbf{n s}$ \\
Days to germination & $\mathbf{n s}$ \\
Days to flowering & $\mathbf{n s}$ \\
Seed Mass & $\mathbf{n s}$ \\
\hline
\end{tabular}


bioRxiv preprint doi: https://doi.org/10.1101/822726; this version posted June 6,2020 . The copyright holder for this preprint (which was not certified by peer review) is the author/funder, who has granted bioRxiv a license to display the preprint in perpetuity. It is made available under aCC-BY-NC-ND 4.0 International license.

Page 29 of 29

Julian C. Bennett Ponsford 